\title{
Sorption of Some Heavy Metal Ions from Aqueous Solutions by Polypropylene Fibers Grafted with Acrylic Acid under the Effect of Gamma Irradiation
}

\section{S. Hassan}

Radiation Chemistry Dept., National Centre for Radiation Research and Technology (NCRRT), P. O .Box; 29 Nasr City, Egypt.

\begin{abstract}
DOLYPROPYLENE FIBERS (PP) grafted with poly acrylic acid (PAAc) were prepared under the effect of gamma irradiation to be used as an adsorbent matrix for $\mathrm{Co}^{2+}$ and $\mathrm{Ni}^{2+}$ ions from aqueous solutions. The different factors which affect the grafting process such as grafting solution, inhibitor concentration, irradiation dose and the monomer concentration were investigated. The grafted PP fibers were characterized by using Fourier-transform infrared (FTIR), X-ray diffraction (XRD), Thermogravimetric analysis (TGA), Differential scanning calorimetery (DSC) and Scanning electron microscopy (SEM). The effect of grafting yield on the mechanical properties of grafted PP fibers was also studied. The different conditions which affect the adsorption capacity of grafted PP fibers towards the metal ions, such as solution $\mathrm{pH}$ and contact time were investigated. The adsorption isotherm was studied according to the Langmuir isotherm model. The effect of regeneration cycles on the adsorption capacity of grafted PP fibers was investigated. Keywords: Polypropylene, $\gamma$-rays, Metal ions, adsorption.
\end{abstract}

Heavy metal pollution can cause serious environmental problems due to its toxic and carcinogenic effects on the natural environment and its accumulation in living organisms (Nriagu et al., 1988 and Liu et al., 2008). The toxicity of heavy metals might be caused by blocking essential functional groups of bio molecules and by disrupting the integrity of bio membranes (Bayramoglu et al., 2002, Jang et al., 2008 and Zhao et al., 2008). In recent years, the removal of hazardous heavy metals from water and soil environments and industrial waste steams has attracted considerable attention. Enhanced metal separation techniques that require less energy with minimal impact on the environment are desirable. 
In order to remove dissolved heavy metal ions from various environments, conventional techniques including chemical precipitation, ion exchange, reverse osmosis, membrane separation, electrochemical treatments and solvent extraction processes are widely used (Akkaya et al., 2008). In general, these techniques are often costly or ineffective, especially in removing heavy metal ions at low concentrations (Laus et al., 2011).

Radiation-induced graft polymerization is widely used to produce high performance chemically active polymer materials for adsorption and separation processes on the basis of various commercial polymers available in different forms (films, fibers, resins, textiles, powders) (Bhattacharya et al., 2004 and Nasef et al., 2004). Direct grafting desirable functional groups to polymer is one of approaches to synthesize polymer adsorbents. Adsorbents can be easily synthesized by radiation-induced graft polymerization. This technique creates an active radical in the trunk polymer by means of ionizing radiation and the polymeric graft chains propagate from the active radical in the trunk polymer (Makay, 1996). In general, synthesized polymers, such as polyethylene and polypropylene, have been used as trunk polymers due to their reactivity in the grafting process and high mechanical strength.

In the present work, radiation grafting of PP fibers with PAAc to use as an adsorbent materials for heavy and toxic metals from waste water was investigated. The main aim is to obtain homogeneously distributed graft copolymer chains with high grafting yield. The properties of the prepared graft copolymer were studied by IR, XRD, TGA and DSC. The mechanical properties of the grafted fibers were also determined.

\section{Experimental}

\section{Materials}

Commercial polypropylene fibers used for this study were manufactured by the Oriental weavers Co., Egypt. and used as a base substrate. AAc monomer, and $1,1^{\prime} 2,2^{\prime}$ tetrachloroethane were purchased from Fluka Chemical Co., Switzerland. Toluene, benzene, methanol and acetone solvents were purchased from El-Nasr Pharmaceutical Chemicals Co., Egypt. Nickel sulphate and Cobalt sulphate were supplied by El-Nasr Pharmaceutical Chemicals Co., Egypt.

Egypt. J. Rad. Sci. Applic., Vol. 27, No. 1-2 (2014) 


\section{Gamma irradiation}

Irradiation was carried out in the Cobalt-60 gamma cell source (made in Russia) installed at the NCRRT, Cairo, Egypt. The direct radiation was used for induced grafting process of AAc onto polypropylene fibers.

\section{Characterization of grafted PP fibers with PAAc}

The prepared grafted PP fibers were analyzed by FTIR, in a wide range wavelength $\left(400-4000 \mathrm{~cm}^{-1}\right)$ and in solid state using Mattson 5000 FTIR spectrometer (Mattson Instruments, Madison, WI). SEM study of the prepared PP fibers was carried out by JSM-640, JEOL at $15 \mathrm{kV}$. The dried sample was sputter-coated with gold using a microscope sputter coater and viewed through the microscope. XRD studies were performed using Philips (PW 1390), using Nickel- filtered $\mathrm{Cu}-\mathrm{K} \alpha$ radiation. The diffractograms were scanned from $2{ }^{\circ} \mathrm{C}$ to $40^{\circ}$ at room temperature. TGA was determined by using Shmadzu-30 (TGA-30) at a heating rate of $10^{\circ} \mathrm{C} / \mathrm{min}$ in air over a temperature rang from room temperature up to $600^{\circ} \mathrm{C}$. DSC was performed using a Perkin Elmer DSC-7 calorimetry equipped with data station. A heating rate of $10{ }^{\circ} \mathrm{C} / \mathrm{min}$ was utilized and the scans were carried out under nitrogen atmosphere. The recorded melting temperatures $\left(\mathrm{T}_{\mathrm{m}}\right)$ were determined.

\section{Mechanical testing}

The mechanical properties including tensile strength $\left(\mathrm{T}_{\mathrm{b}}\right)$ and elongation $\left(\mathrm{E}_{\mathrm{b}}\right)$ to break were tested at room temperature. Every data point is the average of 5 tests. A Mecmesin (Model 10-I) equipped with software was used employing a crosshead speed of $50 \mathrm{~mm} / \mathrm{min}$. In this system the different mechanical parameters were calculated directly.

\section{Determination of metal ions adsorption capacity by grafted PP fibers}

The adsorption capacities $(q)$ of grafted PP fibers towards the different metal ions were determined. A constant weight of dry grafted PP fibers was immersed in a definite volume of metal salt solutions containing a definite concentration of metal ion in flasks under shaking. The remaining metal ions concentrations were determined by using standard solution of EDTA (Skoog et al. 1995). The adsorption capacity $q$ (mg/ g) was calculated according to Equ. 1:

$$
q=\left(C_{o}-C_{e}\right) V / W
$$


where, $\boldsymbol{C}_{\boldsymbol{o}} \& \boldsymbol{C}_{\boldsymbol{e}}$ are the initial and equilibrium metal ion solution concentrations $(\mathrm{mg} / \mathrm{L})$, respectively, $W$ is the wt of grafted PP fibers $(\mathrm{g}), V$ is the volume of metal salt solution (L) (Chiou et al., 2003).

\section{Results and discussion}

\section{Grafting of PP fibers with PAAc}

In the grafting of individual monomers by radiation, it is easy to control the grafting process by controlling the factors affecting the graft yield. The different factors which affect the grafting of PAAc onto PP fibers such as solvent composition, inhibitor concentration, monomer concentration and irradiation dose were investigated. It was found that: (a) The best solvent which gives the highest grafting yield was benzene, in which, its solubility parameter is close to the solubility parameter of PAAc, so its leads to that the polymerization proceeds with high efficiency (Bador, 1991). (b) The addition of $0.1 \%$ of ammonium ferrous sulphate to the aqueous AAc is enough to enhance radiation grafting and minimize the homopolymer formation (Gupta et al., 1989). (c) The grafting yield increases with increasing of the irradiation dose, as a result the free radicals formation, which leads to the increase in the grafting yield (Kerndorff et al., 1980). In this study the maximum irradiation dose used was 10 (kGy), to protect the mechanical properties of grafted PP fibers from the radiation degradation. (d) The grafting yield increases with increasing of the AAc monomer concentration up to $30 \%$, which give $23 \%$ grafting yield at 10 (kGy) radiation dose. By increasing AAc monomer concentration further more $30 \%$, the grafting yield tends to level off as a result of homopolymer formation of PAAc (Langenbach et al., 2003).

\section{Characterization of grafted PP fibers \\ FTIR}

FTIR spectroscopic analysis was used to confirm the formation of graft copolymerization of PAAc onto PP fibers. Fig. 1. shows the IR spectra of PP and grafted PP fibers with PAAc (23\% grafting yield). The characteristic vibration peaks of PP were shown in Fig. 1, as stretching aliphatic - $\mathrm{CH}$ (at 3000-2850 $\mathrm{cm}^{-}$ ${ }^{1}$ ), $\mathrm{C}=\mathrm{C}$ of vinyl group at $\left(1680-1600 \mathrm{~cm}^{-1}\right.$ ) and binding $-\mathrm{CH}_{3}$ (at $1450-1375 \mathrm{~cm}$

${ }^{1}$ ). But for grafted PP with PAAc showed the same characteristic vibration bands of PP were found beside new characteristic absorbed bands of $-\mathrm{CO}$ of carboxylic acid (at 1320-1210 $\mathrm{cm}^{-1}$ ), $-\mathrm{C}=\mathrm{O}$ of carboxylic acid (at 1720-1700 $\mathrm{cm}^{-1}$ ), $-\mathrm{OH}$ of 
carboxylic acid (at $3500 \mathrm{~cm}^{-1}$ ), - $\mathrm{CH}$ out of plane (at $1000-650 \mathrm{~cm}^{-1}$ ) and companied with increasing of $-\mathrm{CH}$ aliphatic and $-\mathrm{CH}_{3}$ groups intensity due to the introducing of PAAc onto the PP skeleton (Bozzi et al., 1987 and Sekine et al., 2010).

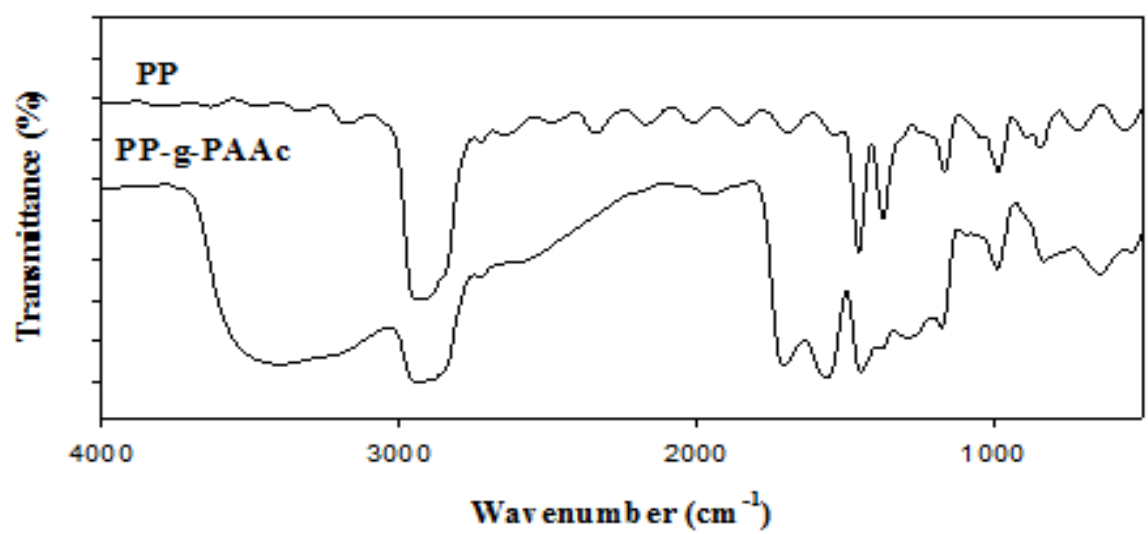

Fig.1. FTIR spectra of PP fibers and PP-g-PAAc (23\%).

$X R D$

The XRD spectra of PP fibers, PP fibers grafted with PAAc (23\%) are showed in Fig. 2. and the XRD parameters are given in Table1. The PP fibers show a definite characterized peak at about $(2 \theta)=16.85$. It can be notice sharp peak intensity represents the crystalline nature of PP fibers.

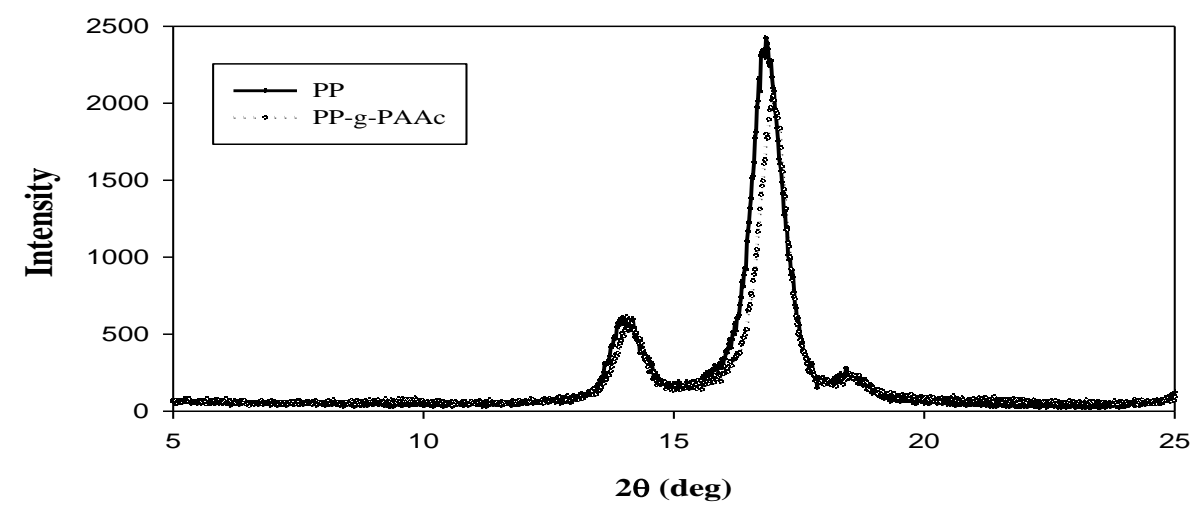

Fig. 2 . XRD scans of polypropylene and PP-g-PAAc fibers.

The intensity of the characterized peak of PP fibers was decreased after grafting with PAAc. This is due to dilution of the crystalline fraction by the incorporation of the amorphous PAAc chains into the polymer matrix (Hegazy et al., 1999). 
Table 1. XRD parameters of PP \& PP-g-PAAc fibers.

\begin{tabular}{|c|c|c|c|}
\hline Substrate fibers & 20 at Strongest peak & $\mathbf{d}\left(\mathbf{A}^{\mathbf{0}}\right)$ & Intensity (kcps) \\
\hline PP & 16.85 & 5.26 & 1497 \\
\hline PP-g-PAAc & 16.96 & 5.22 & 1255 \\
\hline
\end{tabular}

Mechanical properties of the grafted PP fibers

The mechanical properties including $\mathrm{T}_{\mathrm{b}}$ and $\mathrm{E}_{\mathrm{b}}$ at break of PP fibers and grafted PP fibers with AAc at different grafting yield were studied. It must be noted that in the grafting processes of PP at low doses of irradiation were used to protect the PP fibers from irradiation degradation varying AAc contents to achieve different grafting yields (Grazyna et al., 2007). Fig. 3. illustrates the $T_{b}$ of PP fibers and grafted PP fibers with AAc. At different grafting yields. It can be seen that $T_{b}$ were decreased at small percentage of grafting yield due to the degradation effect of irradiation, then it tend to increases with increasing of the grafting yield, due to the formation of cross linked network structure formed via hydrogen bonding of carboxylic acid groups of PAAc graft chain, but it was still less than the $T_{b}$ of ungrafted PP fibers (Cheng et al., 2006). Fig. 3. illustrates also the $E_{b}$ at break of PP fibers before and after grafting with AAc. It can be seen that the $E_{b} \%$ was decreased gradually by increasing of the grafting yield due to the formation of PAAc cross linking, which increase the rigidity of PP fibers (Said et al., 2010).

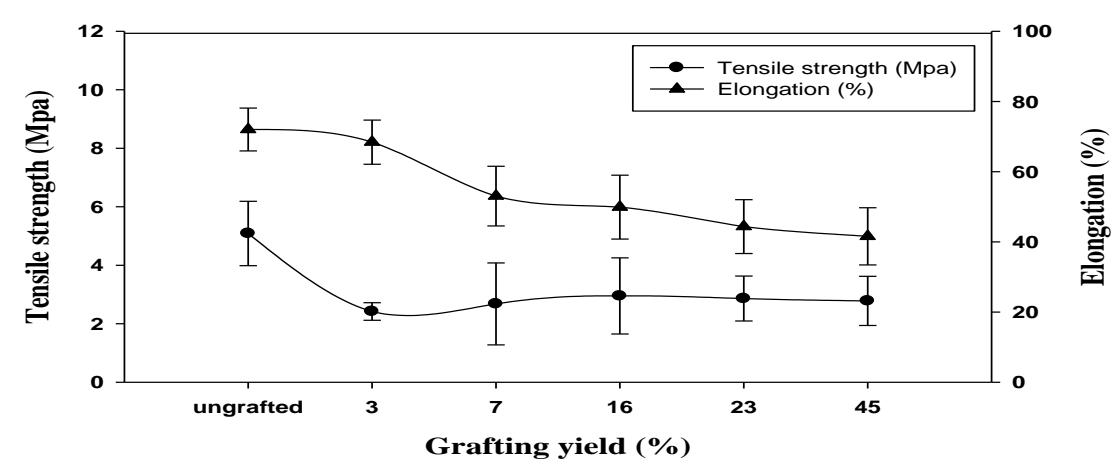

Fig. 3. The $T_{b} \& E_{b}$ at break $\%$ of PP fibers grafted with PAAc (23\%).

$T G A$

The initial TGA thermograms and the rate of thermal decomposition reaction $(\mathrm{dw} / \mathrm{dt})$ or the derivative of the thermogravimetric analysis curve were Egypt. J. Rad. Sci. Applic., Vol. 27, No. 1-2 (2014) 
plotted against temperature for ungrafted and grafted PP fibers with 23\% PAAc as shown in Fig. $4 \& 5$. The effect of graft copolymerization with PAAc on the thermal decomposition (wt loss \%) of PP fibers was summarized in Table 2. From Fig. $4 \& 5$. and Table 2. it can be seen that the thermal degradation of PP fibers proceeds by one step process with a maximum decomposition temperature $\left(\mathrm{T}_{\max }\right)$ at $\sim 309^{\circ} \mathrm{C}$. Degradation started at $\sim 250^{\circ} \mathrm{C}$ and ended at $\sim 600^{\circ} \mathrm{C}$, giving about $1 \%$ residue. In the case of grafted PP fibers, two degradation stages were observed for the decomposition in which, major wt loss of the first step started at $\sim 180^{\circ} \mathrm{C}$ and ended at $\sim 311^{\circ} \mathrm{C}$ with a maximum decomposition temperature $\left(\mathrm{T}_{\max }\right)$ at $\sim 272^{\circ} \mathrm{C}$ with an accompanying of $\sim 42 \%$ wt loss corresponds to the loss of PAAc part in the grafted PP fibers. The second step of decomposition started at $\sim 311^{\circ} \mathrm{C}$ and ended at $\sim 600^{\circ} \mathrm{C}$ with a maximum decomposition temperature $\left(\mathrm{T}_{\max }\right)$ at $\sim 372^{\circ} \mathrm{C}$ with a measured wt loss of $60 \%$.

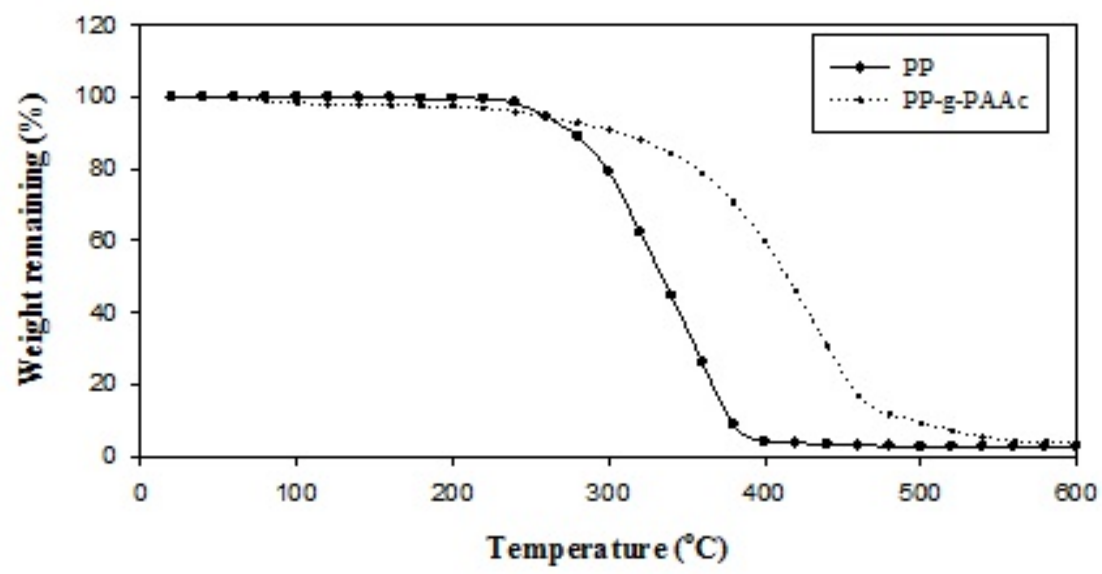

Fig.4. TGA thermograms of PP and PP-g-PAAc (23\%) fibers.

It can be concluded that the thermal stability of PP fibers was increased by grafting with PAAc, in which the maximum decomposition temperature was increased by $\sim 13 \%$ after grafting by $23 \%$ grafting yield of PAAc.

Table 2. Thermal parameters of PP and grafted PP fibers with PAAc.

\begin{tabular}{|c|c|c|c|c|c|c|c|}
\hline \multirow[b]{2}{*}{ PP substrates } & \multicolumn{6}{|c|}{ Wt loss (\%) } & \multirow[b]{2}{*}{$\mathbf{T}_{(\max )}$} \\
\hline & $200^{\circ} \mathrm{C}$ & $300^{\circ} \mathrm{C}$ & $350^{\circ} \mathrm{C}$ & $400^{\circ} \mathrm{C}$ & $450^{\circ} \mathrm{C}$ & $500^{\circ} \mathrm{C}$ & \\
\hline $\mathbf{P P}$ & 0.3 & 20.8 & 73.9 & 95.9 & 97 & 97.2 & 309.1 \\
\hline PP-g- PAAc (23\%) & 2.5 & 9 & 21.2 & 40.1 & 83.3 & 90.7 & $272,371.6$ \\
\hline
\end{tabular}




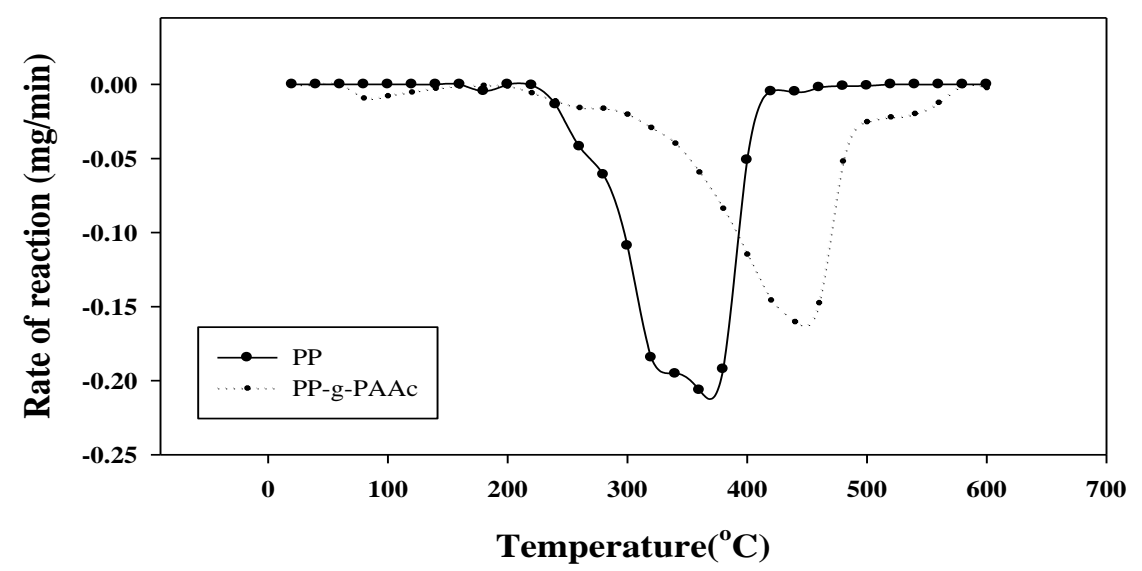

Fig. 5. The rate of thermal decomposition reaction of PP and PP-g-PAAc.

\section{DSC}

The effect of graft copolymerization of PP fibers with PAAc on the crystalline melting temperature of PP fibers was investigated by DSC thermal analysis. Fig. 6. shows the DSC scans of the crystalline melting transition behaviour for the ungrafted and grafted PP fibers with PAAc at a graft yield $23 \%$. It can be seen that $\mathrm{T}_{\mathrm{m}}$ of PP fibers was $\sim 165^{\circ} \mathrm{C}$ and its $\Delta \mathrm{Hm}$ was 59.2. After graft copolymerization with PAAc, $\mathrm{T}_{\mathrm{m}}$ was decreased to $\sim 148^{\circ} \mathrm{C}$ and the $\triangle \mathrm{Hm}$ decreased also to 15.5 . This could be attributed to the introduction of PAAc grafted chain into the PP fiber matrix, causing change in morphological structure (Hegazy, 2012). In which the PAAc have a lower $T_{m}$ than PP fibers at $\sim 139$ (Elias et al., 1998).

\section{SEM}

Characterization of the PP fibers by SEM was made to compare the difference in the physical appearance of ungrafted and graft copolymerized PP fibers with PAAc (23\% grafting yield). SEM photographs of PP fibers and PP graft copolymerized with PAAc are given in Fig. 7. The smooth crystalline appearance of ungrafted PP fibers was shown in Fig. 7(a). On the other hands, it can be seen that the PP fibers became coarser, groovy and the diameter average was increased by $\sim 20 \%$ due to the formation of PAAc upon the surface of PP fibers as shown in Fig. 7(b).

Egypt. J. Rad. Sci. Applic., Vol. 27, No. 1-2 (2014) 

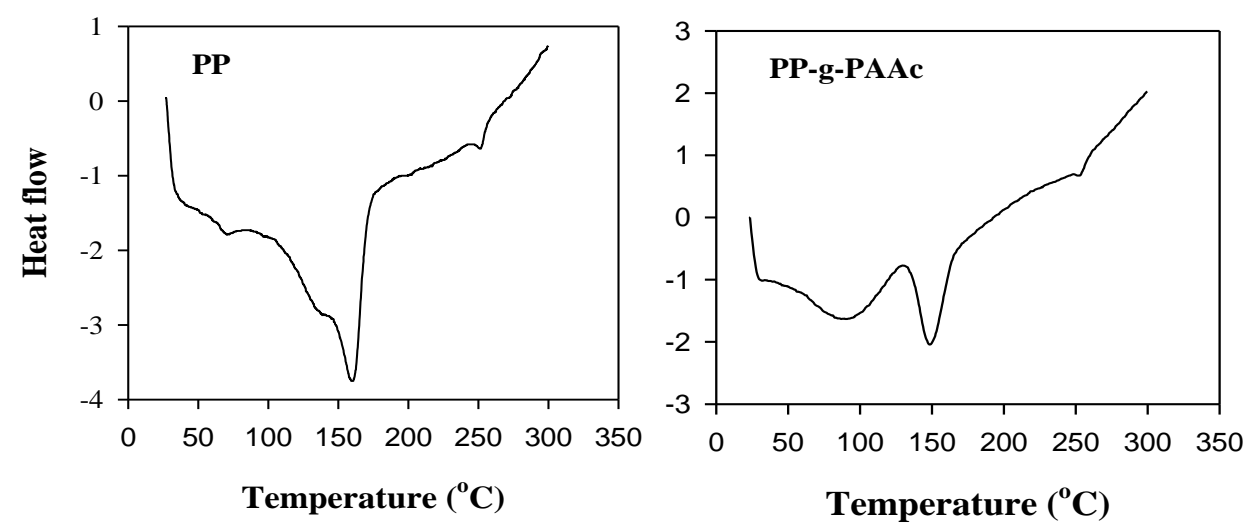

Fig. 6. DSC scan of crystalline melting transition for ungrafted and grafted PP fibers with PAAc (23\%).

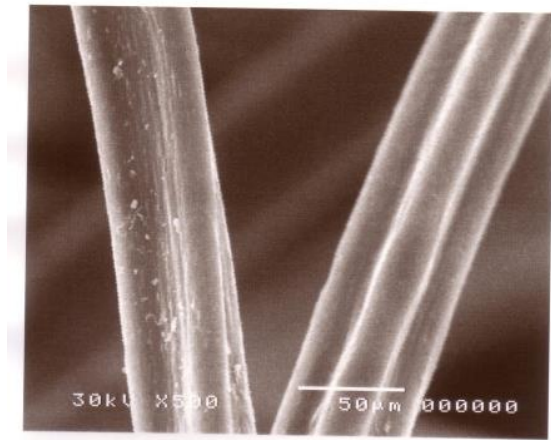

(a)

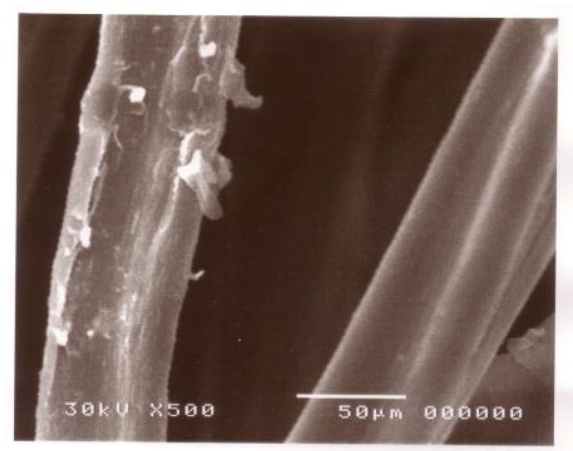

(b)

Fig.7. SEM micrographs of the surface morphology of: (a) ungrafted PP fibers \& (b) grafted PP fibers with PAAc (23\%).

\section{Metal ions adsorption by the grafted PP fibers}

The influence of the different parameters, which affecting the adsorption capacity of grafted PP fibers towards the metal ions such as $\mathrm{pH}$, contact time was investigated as shown in Fig. 8.

\section{Effect of $\mathrm{pH}$ on the metal ions adsorption capacity}

The $\mathrm{pH}$ is known to be an important variable affecting the adsorption affinity of metal ions. It can influence the protonation of the functional groups on the $q$ as well as the solution chemistry of the heavy metal ions. Fig. 8. shows the effect of solution $\mathrm{pH}$ on the adsorption capacity of $\mathrm{Co}^{2+}$ and $\mathrm{Ni}^{2+}$ for grafted PP fibers with PAAc, at initial concentration of metal salts $1000 \mathrm{mg} / \mathrm{l}$ for $60 \mathrm{~min}$ 
at the room temperature. The $\mathrm{pH}$ ranges under investigation were from 2-7, to avoid the significant formation of precipitation at alkaline medium for the metal ions (Yiming et al., 2012). The adsorption capacity of $\mathrm{Co}^{2+}$ and $\mathrm{Ni}^{2+}$ was found to increase when the $\mathrm{pH}$ range was increased from 2 to 3 , then it tend to increase gradually with increasing of the $\mathrm{pH}$ range. At low $\mathrm{pH}$ range $(\mathrm{pH} 2)$, more $\mathrm{H}^{+}$competed with metal ions for adsorption sites, which made it more difficult for metal ions to bind to activated sites. Also, carboxylic groups existed in the form of $-\mathrm{COOH}$ and $-\mathrm{COO}-$, which can hinder the interaction between grafted PP fibers and metal ions. On the other hand, at higher $\mathrm{pH}$ range $(\mathrm{pH} \geq 3)$, more ionized carboxylic groups were available, increasing the interaction between the carboxylic groups and metal ions and causing an increasing in $\mathrm{Co}^{2+}$ and $\mathrm{Ni}^{2+}$ adsorption capacity (Yiming et al., 2012). It was found also that at the same conditions, the adsorption capacity of $\mathrm{Co}^{2+}$ ion by PP grafted fibers with PAAc was grater than it for $\mathrm{Ni}^{2+}$ ion, which could be attributed to the complex stability formed between the metal ion and polymer functional groups. The higher stability of complex, the higher the affinity is obtained. In this study, the complex stability of $\mathrm{Co}^{2+}$ was more than it for $\mathrm{Ni}^{2+}$, which gives higher adsorption capacity (Hegazy, 2012).

\section{Effect of contact time on the metal ions adsorption capacity}

The effect of contact time on the adsorption capacity of metal ions at various contact times (15, 30, 60, 120, 150 and $200 \mathrm{~min})$ was studied. Fig. 8. shows the effect of contact time on the adsorption capacity of $\mathrm{Co}^{2+}$ and $\mathrm{Ni}^{2+}$ ions by grafted PP fibers with $23 \%$ PAAc, at initial concentration of metal salts $1000 \mathrm{mg} / \mathrm{l}$. The adsorption capacity for the both of metal ions under investigation $\left(\mathrm{Co}^{2+}\right.$ and $\left.\mathrm{Ni}^{2+}\right)$ was increased rapidly at the beginning of the contact time up to $60 \mathrm{~min}$, then tend to level of with increasing of the contact time, in which more than $85 \%$ of the total adsorbed metal ions was taken at the first $h$. This could be attributed to the presence of many adsorbed sites of the grafted PP fibers not complexed with any metal ions at starting time. After 60 min, the adsorbed metal ions remained nearly constant and hardly increased (Yiming et al., 2012). It was found also that at the same conditions, the adsorption capacity of $\mathrm{Co}^{2+}$ ion by PP grafted fibers with PAAc was grater than it for $\mathrm{Ni}^{2+}$ ion, due to its higher complex stability.

Egypt. J. Rad. Sci. Applic., Vol. 27, No. 1-2 (2014) 

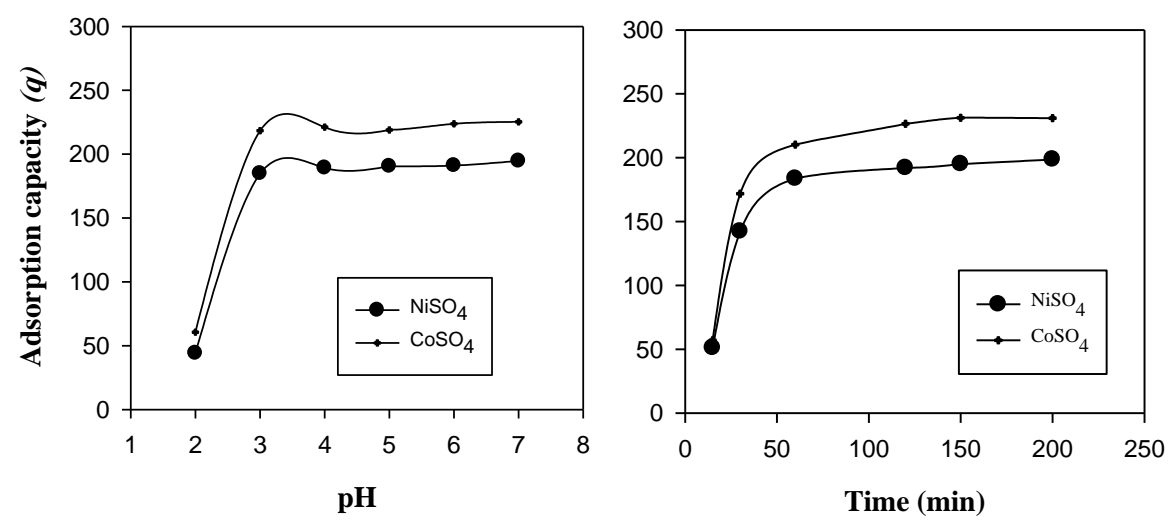

Fig. 8. The effect of different $\mathrm{pH}$ ranges and contact time on the metal ions adsorption capacity by PP-g-PAAc fibers.

\section{Adsorption isotherm}

The adsorption isotherms are important for the discussion of the interaction of the adsorbent molecules with the adsorbent surface. As shown in Fig. 9. the adsorption capacity increases with increasing of the initial concentrations of the metal ion concentration, for both of $\mathrm{Ni}^{2+}$ and $\mathrm{Co}^{2+}$. This could be attributed to that the increasing in the metal ion concentrations can accelerate the metal ion diffusion into the polymeric network. The maximum adsorption capacity of grafted PP fibers towards the metal ions can be determined by using the Langmuir model (Zheng et al., 2011). The Langmuir isotherm assumes that the adsorption process occurs at specific homogeneous sites on the PP grafted fibers and is the most commonly used for monolayer adsorption process, as shown in Equ. 2.

$$
q_{e}=q_{m} b C_{e} d 1+b C_{e}
$$

where, $q_{e}$ is the equilibrium adsorption capacity of metal ion on grafted PP fibers $(\mathrm{mg} / \mathrm{g}), C_{e}$ is the equilibrium metal ion concentration $(\mathrm{mg} / \mathrm{l}), q_{m}$ is the monolayer adsorption capacity of the grafted PP fibers $(\mathrm{mg} / \mathrm{g})$ and $b$ is the Langmuir adsorption constant (L/mg).

The slopes and intercepts of plots of $C_{e} / q_{e}$ versus $C_{e}$ were used to determine $q_{m}$ and $b$ as shown in Fig. 10, in which $q_{m}, b$ and correlation coefficient $\left(r^{2}\right)$ were found to be $426.1,1.346$ and 0.98926 for $\mathrm{Ni}^{2+}$, while they were $325.5,1.089$ and 0.98926 for $\mathrm{Co}^{2+}$ metal ion.

Egypt. J. Rad. Sci. Applic., Vol. 27, No. 1-2 (2014) 


\section{Desorption and regeneration of grafted PP fibers}

The desorption of the grafted PP fibers after usage for metal ions adsorption was achieved by soaking in $0.1 \mathrm{~mol} \mathrm{HNO}_{3}$ for $60 \mathrm{~min}$, on water bath shaker followed by washing with distilled water. The regeneration process was done by using of $0.1 \mathrm{~mol} / \mathrm{l} \mathrm{NaOH}$. The regenerated PP fibers were reused for 5 cycles. The $q$ of the grafted PP fibers towards metal ions was determined with repeating the adsorption cycles. From Fig. 11, it can be seen that the $q$ of the grafted PP fibers was decreased by repeating the regeneration cycles, nevertheless, the type of adsorbed metal ions in which, it decreased to 83.16 and 92.65\% compared to the initial adsorption capacity for $\mathrm{Ni}^{2+}$ and $\mathrm{Co}^{2+}$ ions, respectively, after the first cycle of regeneration, up to 13.9 and $20.59 \%$ after the fifth cycle of regeneration. Thus, It may conclude that the regenerated grafted PP fibers is suitable up to two cycles, in which it loses about 64 and $78 \%$ of its adsorption capacity towards $\mathrm{Ni}^{2+}$ and $\mathrm{Co}^{2+}$ ions, respectively.

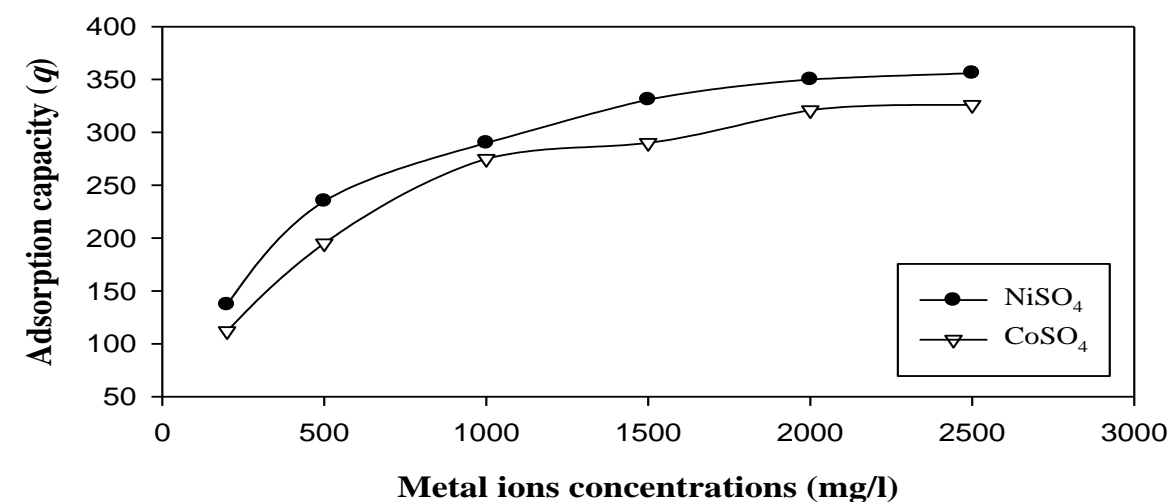

Fig. 9. Effect of the initial ion concentrations on the $q$ of metal ions by grafted PP fibers with PAAc.
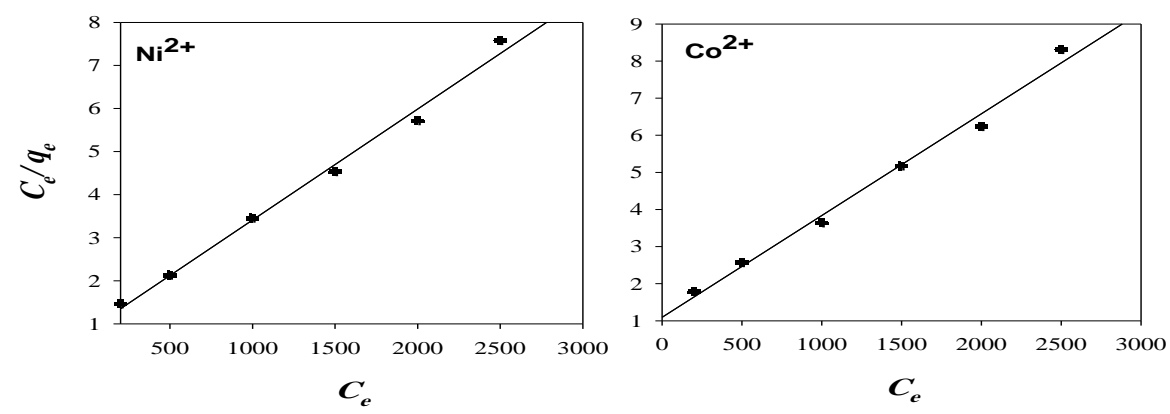

Fig. 10. The Langmuir plots for the $q$ capacity of the metal ions by grafted PP fibers with PAAc.

Egypt. J. Rad. Sci. Applic., Vol. 27, No. 1-2 (2014) 


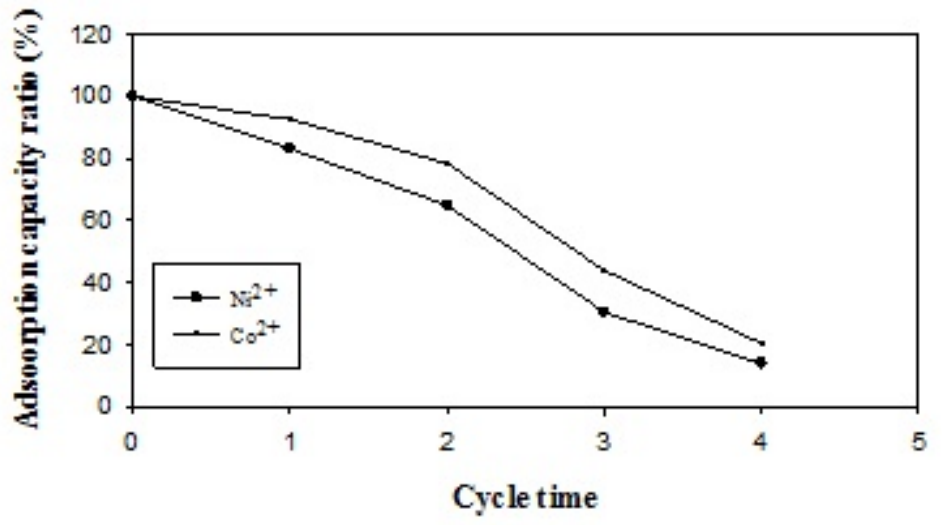

Fig. 11. The effect of regeneration times on the adsorption capacity of grafted PP fibers.

\section{Conclusion}

PP fibers were graft copolymerized by PAAc under the effect of low dose of gamma irradiation. From the results, it can be concluded that:

- The higher graft yield with suitable mechanical properties of PP fibers was obtained at $10 \mathrm{kGy}$ irradiation dose, by using $30 \%$ monomer concentration.

- The higher adsorption capacity of grafted PP fibers was at $\mathrm{pH} \leq 3$ and contact time for $60 \mathrm{~min}$.

- The adsorption isotherm was according to the Langmuir model.

- The grafted PP fibers can be regenerated and reused with acceptable adsorption capacity up to 2 cycles.

\section{References}

Akkaya, R. and Ulusoy, U. (2008) Disruptive features of chitosan entrapped in polyacrylamide hydrogel for $\mathrm{pb}^{2+}, \mathrm{UO}_{2}^{2+}$ and $\mathrm{Th}^{4+}$. J. Hazard. Mater., 151, 380 .

Bador, G. (1991) Structure investigation of polymer; Elis Horwood Limited; London. p.127.

Bayramoglu, G., Arica, M. Y. and Bektas, S. (2002) Removal of $\mathrm{Cd}(\mathrm{II}), \mathrm{Hg}(\mathrm{II})$, and $\mathrm{Pb}$ (II) ions from aqueous solution using $\mathrm{P}$ (HEMAl chitosan) membrane. $J$. APPl. Polym. Sci., 106, 169.

Bhattacharya, A. and Misra, B. N. (2004) Grafting: a versatile means to modify polymers: techniques, factors and applications. Prog. Polym. Sci., 29, 767.

Bozzi, A. and Chapiro, A. (1987) The native of the initiating centers of grafting in airirradiated perfluoro polymers. Eur. Polym. J., 23, 255.

Egypt. J. Rad. Sci. Applic., Vol. 27, No. 1-2 (2014) 
Cheng, B., Jiao, X. and Kang, W. (2006) Studies on grafting of acrylic acid onto polypropylene melt-blown nonwovens induced by electron-beam preirradiation. J. APPl. Polym. Sci., 102, 4971.

Chiou, M. S., Kuo, W. S. and Li, H. Y. (2003) Removal of reactive dye from wastewater by adsorption using ECH cross-linked chitosan beads as medium. J. Environ. Sci. and Helth, 38, 2621.

Elias, P., John, D. and John, T. (1998) Azo cross-linked poly(acrylic acid) for colonic delivery and adhesion specificity: synthesis and characterization. J. Control. Release, 52, 291.

Grazyna, P., Krzysztof, M. and Andrzej, R. (2007) Radiation degradation of blends of polypropylene (polyethylene-co-vinyl acetate). Radiat. Phys. Chem., 76, 1312.

Gupta, B. D. and Chapiro, A. (1989) Preparation of ion-exchange membranes by grafting acrylic acid into pre-irradiated polymer films. Eur. Polym. J., 25, 1137.

Hegazy, D. (2012) Selectivity of acrylic acid radiation grafted non-woven polypropylene sheets towards $\mathrm{Cu}, \mathrm{Ni}$ and Co heavy metals ions. J. Chem. Engen., 1, 42.

Hegazy, E. A., Kamal, H., Khalifa, N. A. and Mahmoud, Gh. A. (1999) Ionexchange membranes for metal ions separation. Iran. Polym. J., 8, 223.

Jang, S. H., Jeonga, G. Y., Mina, B. G., Lyoob, W. S. and Lee, S. C. (2008) Preparation and lead ion removal property of hydroxyapatite/poly acrcylamide composite hydrogels. J. Hazard. Mater., 159, 294.

Kerndorff, H. and Schnitzer, M. (1980) Sorption of metals on humic acid. Geochim Cosmochim Acta, 44, 1701.

Langenbach, M. R., Schmidt, J. and Zirngibl, H. (2003) Comparison of biomaterials in the early postoperative period. Surg. Endosc., 17, 1105.

Laus, R. and De Favere, V. T. (2011) Competitive adsorption of $\mathrm{Cu}$ (II) and $\mathrm{Cd}(\mathrm{II})$ ions by chitosan crosslinked with epichlorohydrine-triphosphate. BiosourceTechnol., 102, 8769.

Liu, C., Bai, R. and Ly, Q. S. (2008) Selective removal of copper and lead ions by diethylene triamine-functionalized adsorbant: Behaviors and mechanisms. Water Res., 42, 1511.

MaKay, G. (1996) Use of Adsorbents for the Removal of Pollutants from Wastewaters", CRC Press, Boca Raton, FL, USA, p. 128.

Nasef, M. M. and Hegazy, E. A. (2004) Preparation and applications of ion exchange membranes by radiation-induced grafting copolymerization of polar monomers onto polar films. Prog. Polym. Sci., 29, 499.

Nriagu, J. O. and Pacyna, J. M. (1988) Quantitative assessment of worldwide contamination of air, water and soils by trace metals. Nature, 333, 134.

Said, H. M., Sokker, H. H. and El-Hag Ali, A. (2010) Acrylation of pre-irradiated polypropylene and its application for removal of organic pollutions. Radiat. Phys. Chem., 79, 534.

Egypt. J. Rad. Sci. Applic., Vol. 27, No. 1-2 (2014) 
Sekine, A., Seko, N., Tamada, M. and Suzuki, Y. (2010) Biodegradable metal adsorbent synthesized by graft polymerization onto nonwoven cotton fabric. Radiat. Phys. Chem., 79, 16.

Skoog, D. A., West, D. M. and Holler, F. J. (1995) Fundamentals of Analytical Chemistry. $7^{\text {th }}$ ed., New Yourk, USA, pp. 345-381.

Yiming, Z., Liangliang, Z., Shiyu, F., Liming, Z. and Huaiyu, Z. (2012) Adsorption behavior of $\mathrm{Cd}^{2+}, \mathrm{pb}^{2+}$, and $\mathrm{Ni}^{2+}$ from aqueous solutions on cellulose- based hydrogels. Bioresources, 7, 2752.

Zhao, H. and Mitomo, H. (2008) Adsorption of heavy metal ions from aqueous solution onto chitosan entrapped CM-cellulose hydrogels synthesized by irradiation. J. APPl. Polym. Sci., 110, 1388.

Zheng, Y., Huan, D. and Wang, A. (2011) Chitosan-g-poly (acrylic acid hydrogel with crosslinked polymeric networks for $\mathrm{Ni}^{2+}$ recovery. Anal. Chim. Acta, 687, 193.

(Received: 10/02/2014;

accepted: 19/05/2014) 


\section{استخلاص بعض ايونـات العناصر الثقيلة من المحاليل المائية

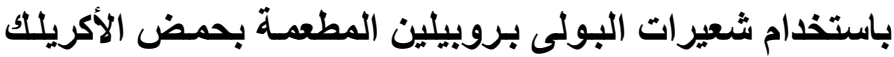 تحت تاثير اشعة جاميرات البول \\ محمود صلاح الدين حسن

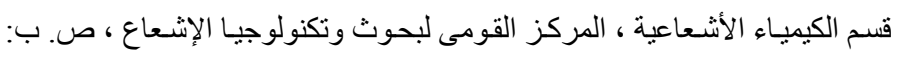

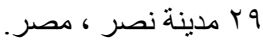

فى هذا البحث تم تطعيم شعير ات البولى بروبيلين باستخدام حمض الاكريلك تحت

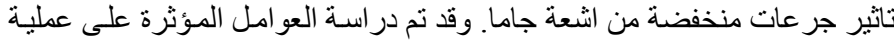

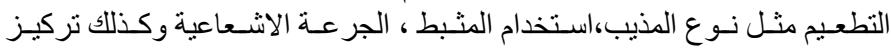

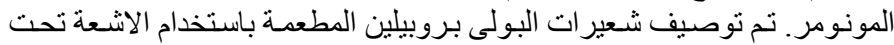

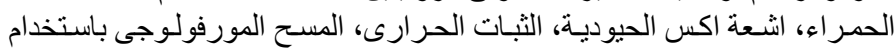

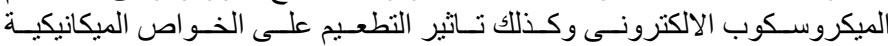

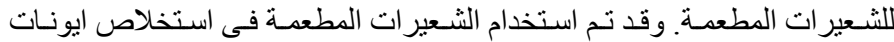

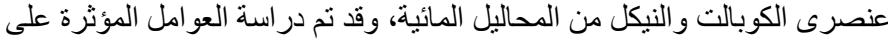

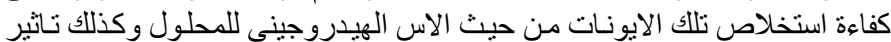

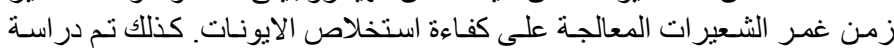

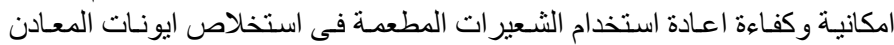
اكثرمن مرة بعد اعادة تنثيطها.

Egypt. J. Rad. Sci. Applic., Vol. 27, No. 1-2 (2014) 